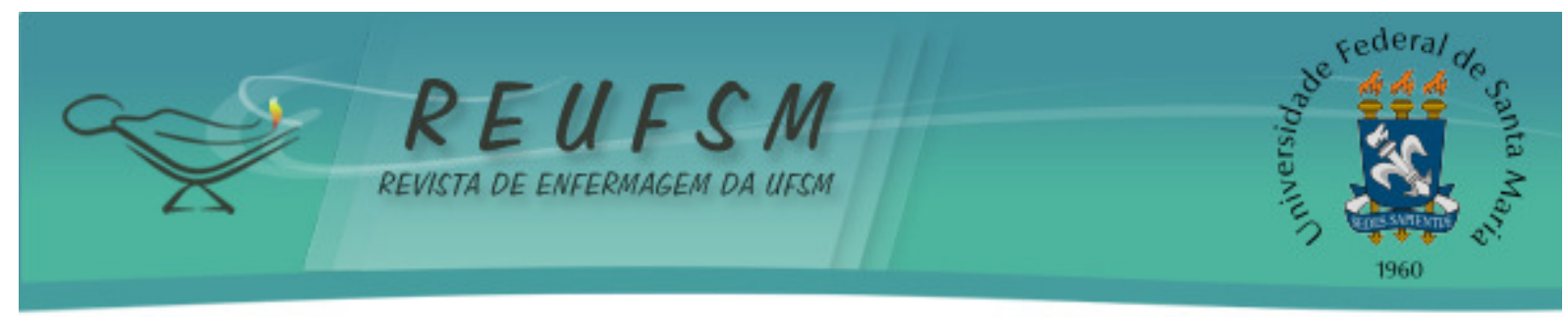

ARTIGO ORIGINAL

\title{
OPINIÃO DE TÉCNICOS DE ENFERMAGEM SOBRE A POLÍTICA DE ATENÇÃO À SAÚDE DO HOMEM
}

\section{OPINION OF NURSING TECHNICIANS ON THE HEALTH CARE POLICY FOR MEN OPINIÓN TÉCNICOS DE ENFERMERÍA EN LA POLÍTICA DE ATENCIÓN PARA LA SALUD DEL HOMBRE}

\author{
Rosineide Santana de Brito ${ }^{1}$ \\ Danyelle Leonette Araújo dos Santos ${ }^{2}$ \\ Nathaly Ellen Maria Silva Ferreira ${ }^{3}$
}

Doi: $10.5902 / 2179769210721$

RESUMO: Objetivo: identificar a opinião de técnicos de enfermagem atuantes na Estratégia Saúde da Família sobre a Política Nacional de Atenção Integral à Saúde do Homem. Método: estudo exploratório, descritivo, quantitativo, realizado com 21 técnicos de enfermagem trabalhadores de quatro Unidades Saúde da Família, do município de Natal/RN, Brasil. Os dados foram coletados em janeiro/fevereiro de 2013, utilizando formulário contendo variáveis sociodemográficas e relativas ao objeto de estudo. A análise dos dados baseou-se na estatística descritiva. O estudo teve aprovação do Comitê de Ética em Pesquisa da Universidade Federal do Rio Grande do Norte, CAAE 0114.0.051.000-11. Resultados: alguns entrevistados demonstraram desconhecer a política voltada à saúde masculina, porém, a totalidade da amostra emitiu opinião favorável sobre sua existência, justificando este fato pelo seu caráter preventivo. Conclusão: evidenciou-se a necessidade dessa política ser melhor propagada entre os profissionais das equipes de saúde, visando contribuir para ampliar a assistência a saúde do homem.

Descritores: Estratégia saúde da família; Saúde do homem; Enfermagem em saúde pública.

ABSTRACT: Objective: to identify the opinion of the nursing technicians working in the Family Health Strategy about the Brazilian Comprehensive Health Care Policy for Men. Method: an exploratory and descriptive quantitative study was conducted with 21 nursing technicians working at four Basic Health Units, in the city of Natal/RN, Brazil. Data were collected in January/February 2013, by means of forms which focused on sociodemographic variables and related to the object of study. The data analysis was carried out using descriptive statistics. This study was approved by the Research Ethics Committee of the Federal University of Rio Grande do Norte, CAAE 0114.0.051.000-11. Results: some respondents have shown lack of knowledge on the policies for men's health. However, the whole sample positioned themselves favorably to its existence and justified it by the preventive and educational character of the policy. Conclusion: it was highlighted that it is necessary for the policy to be better disseminated among professionals of health teams, in order to contribute to the improvement of men's health care.

Descriptors: Family Health Strategy; Men's health; Public health nursing.

RESUMEN: Objetivo: identificar la opinión de técnicos de enfermería actuantes en la Estrategia Salud de Familia sobre la Política Nacional de Atención Integral a la Salud del

\footnotetext{
1 Enfermeira. Doutora em Enfermagem pela Universidade de São Paulo Ribeirão Preto. Professora Associada IV da Universidade Federal do Rio Grande do Norte (UFRN). Natal, RN, Brasil. E-mail: rosineide@ufrnet.br.

2 Enfermeira. Mestre em Enfermagem pelo Programa de Pós-graduação em Enfermagem da UFRN. Natal, RN, Brasil. E-mail: danyleonette@gmail.com.

${ }^{3}$ Enfermeira pela Universidade Federal do Rio Grande do Norte. E-mail: nathaly_ellen@yahoo.com.br.
} 


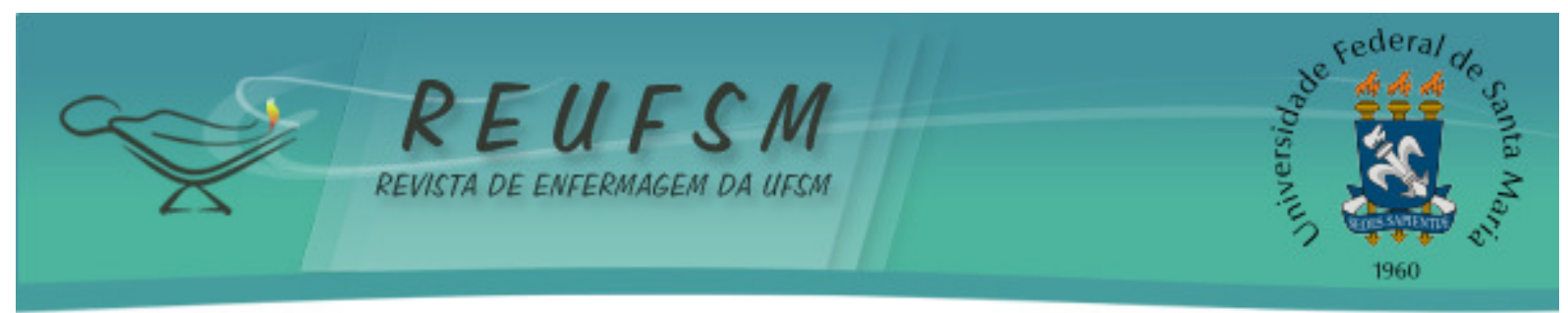

Hombre. Método: estudio exploratorio, descriptivo, cuantitativo, con 21 técnicos de enfermería trabajadores de cuatro Unidades Básicas de Salud, en Natal (RN, Brasil). Los datos fueron colectados en enero/febrero de 2013, mediante formulario con variables sociodemográficas y relativas al objeto de estudio. El análisis de datos se basó en estadística descriptiva. Estudio aprobado por el Comité de Ética en Investigación de la Universidad Federal de Rio Grande do Norte, CAAE 0114.0.051.000-11. Resultados: algunos entrevistados demostraron desconocer la política orientada a la salud masculina, pero el conjunto de la muestra emitió opinión favorable sobre su existência, justificada por su carácter preventivo. Conclusión: es necesario que esta política sea mejor divulgada entre los profesionales de salud, para ampliar la asistencia a la salud masculina.

Descriptores: Estrategia de salud familiar; Salud del hombre; Enfermería en salud pública.

\section{INTRODUÇÃO}

O Sistema Único de Saúde (SUS) foi criado a partir de amplos debates ocorridos na VIII Conferência Nacional de Saúde, em março de 1986, e estabelecido formalmente pela Constituição Federal de 1988. Em sua proposta, a saúde é direito de todos e dever do Estado, com vistas a democratização das ações e dos serviços de saúde. ${ }^{1}$

O SUS norteia-se pelos princípios doutrinários da universalidade, equidade e integralidade da assistência de forma a garantir um maior acesso dos cidadãos às estratégias de saúde. Entretanto, a criação desse sistema por si só não garantiu, na prática, as conquistas legais que objetivava, pois encontrou obstáculos políticos, financeiros e institucionais para a sua implementação. ${ }^{2}$

Diante desta realidade e também com o objetivo de reorientar o modelo assistencial hospitalocêntrico predominante naquela época, o Ministério da Saúde (MS) implementou, em 1994, o Programa Saúde da Família (PSF), o qual posteriormente, em 1996, passou a ser denominado Estratégia Saúde da Família (ESF). A ESF prioriza ações de prevenção, promoção e recuperação da saúde das famílias, organizando a atenção básica de acordo com os supracitados princípios doutrinários do SUS, além dos princípios organizativos: participação social, descentralização, regionalização e hierarquização do sistema. ${ }^{1,3}$

Contudo, para que estes princípios sejam alcançados e a comunidade tenha acesso à assistência em saúde, faz-se necessária a atuação de equipes multiprofissionais responsáveis pelo atendimento na ESF. Tais equipes são compostas minimamente por um médico, um enfermeiro, um auxiliar/técnico de enfermagem e seis agentes comunitários de saúde, podendo ainda contar com um dentista, um auxiliar de consultório dentário e um técnico em higiene bucal. ${ }^{4}$

Com relação ao técnico de enfermagem, esse profissional exerce atribuições específicas na equipe, tais como: participação e realização de atividades e procedimentos realizados na Unidade Saúde da Família (USF), domicílio ou em outros espaços comunitários; gerenciamento de insumos necessários ao funcionamento da USF e a realização de ações educativas em saúde com grupos populacionais específicos e famílias. ${ }^{1}$ Sobre este assunto, estudos mostram a inexistência de programas cujo enfoque seja a população masculina, a qual tende a permanecer distante dos serviços oferecidos pela atenção primária, ficando, assim, alheia às formas de prevenção e autocuidado. ${ }^{5-6}$

Somam-se a isso, outros fatores que dificultam a procura por assistência em saúde pelo homem, a exemplo, o estereótipo de gênero atribuído a estes indivíduos. Pois, na sociedade, existe um perfil pré-estabelecido aos homens, os quais devem adotar características específicas como força, poder e virilidade. Em função disto, a busca pelo 


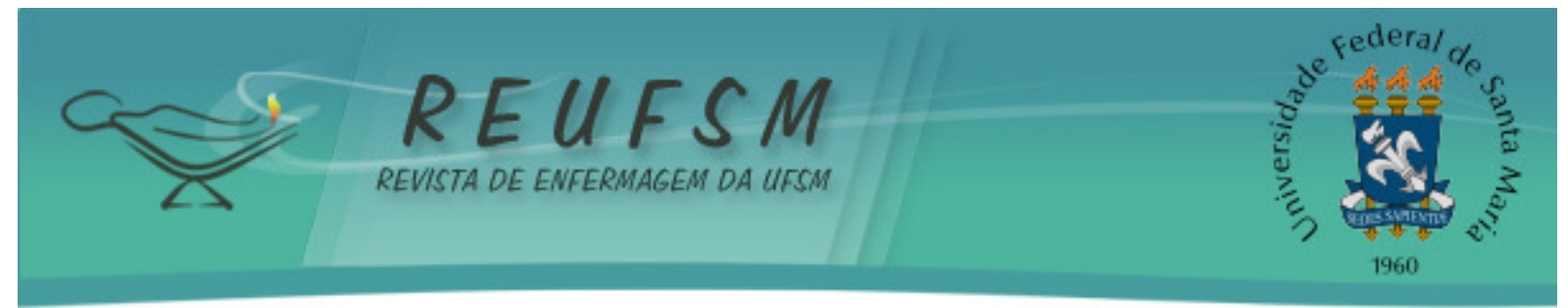

cuidado à saúde é vista como sinal de fraqueza, pois o cuidar é um atributo peculiar do grupo feminino. ${ }^{5,7}$

Mediante esta realidade desfavorável aos homens e visando reduzir os índices de morbidade e mortalidade que acometem este subgrupo populacional, o MS lançou, em 2009, a Política Nacional de Atenção Integral à Saúde do Homem (PNAISH). Esta tem o objetivo de melhorar as condições de saúde da população masculina e facilitar o seu acesso aos serviços assistenciais, atendendo-os nos diferentes níveis de atenção de forma articulada com as demais políticas existentes no país. ${ }^{8}$

Todavia, para a concretização dos objetivos da referida política, é de fundamental importância o envolvimento dos profissionais atuantes nas equipes da ESF para que estes, no exercer de suas funções, possam atuar junto aos homens, estimulando-os a aderirem às ações oferecidas pelos serviços de atenção primária, tornando tais espaços também masculinos.

Tendo em vista o papel do técnico de enfermagem como um educador em saúde e, sendo este profissional parte integrante da equipe de enfermagem, o estudo está pautado na seguinte questão de pesquisa: como os técnicos de enfermagem veem a implantação de uma política específica para a população masculina? Frente a este questionamento, foi traçado o seguinte objetivo: verificar a opinião dos técnicos de enfermagem atuantes na Estratégia Saúde da Família sobre a Política Nacional de Atenção Integral à Saúde do Homem.

Considera-se que a relevância deste estudo está em contribuir com a produção científica a respeito deste assunto, visto o levantamento de literatura ter mostrado reduzido número de trabalhos sobre esta temática. Além disso, acredita-se que seus resultados fornecerão subsídios para promover debates sobre a PNAISH e, consequentemente, possibilitar sua real implementação nos espaços de atenção primária.

\section{MÉTODO}

A pesquisa é um recorte do projeto intitulado "Concepções de profissionais de saúde sobre a inserção de programas específicos para atender o homem na atenção primária à saúde". O referido projeto foi aprovado pelo Comitê de Ética em Pesquisa da Universidade Federal do Rio Grande do Norte em julho de 2011, sob parecer n ${ }^{\circ} 293 / 2011$ e CAAE n ${ }^{\circ}$ 0114.0.051.000-11.

Trata-se de um estudo exploratório, descritivo, com abordagem quantitativa, desenvolvido em quatro USF localizadas no Distrito Sanitário Oeste, do município de Natal, Rio Grande do Norte, Brasil. A escolha pelo supracitado Distrito se deu por ser este o que possuía maior número de equipes da ESF, oferecendo, portanto, condições para o desenvolvimento da investigação, visto existir contingente significativo de profissionais atuantes neste modelo assistencial. Assim, dentre as 12 USF inseridas nesta área distrital, selecionou-se quatro por meio de sorteio aleatório.

Participaram do estudo 21 técnicos de enfermagem, no universo de 29 profissionais, que trabalhavam nas equipes da ESF das USF selecionadas. Estes deveriam atender a critérios de inclusão previamente estabelecidos, tais como: ser técnico de enfermagem e estar atuando nas USF pesquisadas. Dessa forma, excluíram-se do estudo aqueles profissionais que se encontravam em férias ou licença médica. É válido salientar que, o quantitativo da amostra se deu por três técnicos de enfermagem terem se recusado de participar do estudo, um encontrava-se de férias e outros quatro estavam afastados de suas funções por motivo de doença.

A coleta de dados ocorreu nos meses de janeiro e fevereiro de 2013. Os possíveis participantes da pesquisa foram contatados pela entrevistadora no intuito de verificar 


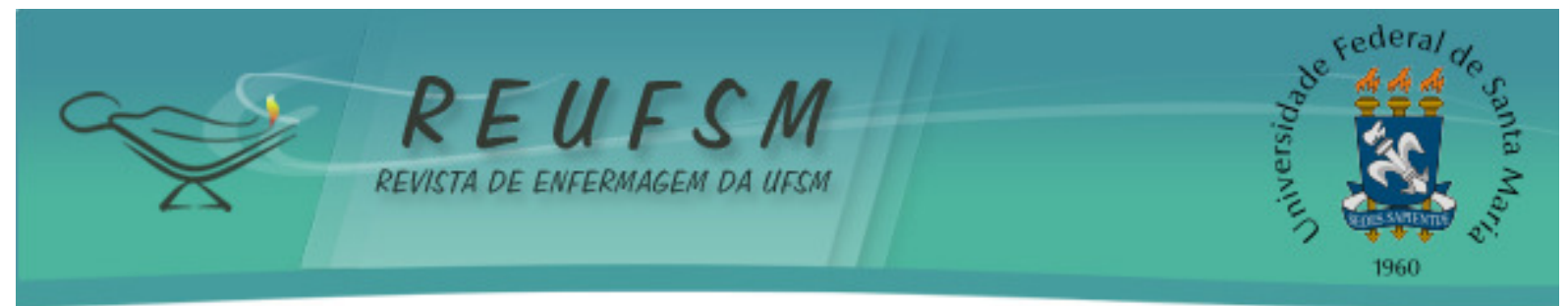

possibilidade em participar do estudo. Neste momento, caso demonstrassem interesse e disponibilidade, a entrevista era realizada mediante a assinatura do Termo de Consentimento Livre e Esclarecido sob a garantia do anonimato e a utilização das respostas apenas para fins científicos, honrando os princípios éticos e legais de acordo com a Resolução 196/96 do Conselho Nacional de Saúde no que se refere à pesquisa com seres humanos. ${ }^{9}$

Como meio de operacionalizar a coleta de dados, utilizou-se um formulário contendo variáveis sociodemográficas, de caráter profissional e relativas ao objeto de estudo. As respostas foram tabuladas em planilhas no Microsoft Office Excel 2010 e submetidas a um processo estatístico descritivo. Posteriormente, os dados foram organizados em forma de tabelas. A análise e discussão dos resultados teve respaldo na PNAISH e na literatura científica acerca da saúde do homem no contexto da atenção primária.

\section{RESULTADOS E DISCUSSÃO}

A partir dos dados obtidos junto aos 21 técnicos de enfermagem, foram verificadas as variáveis sexo, idade, escolaridade e tempo de atuação como Técnico de Enfermagem, representadas na tabela 1.

Tabela 1 - Distribuição dos participantes da pesquisa quanto aos dados sociodemográficos relativos ao sexo, idade, estado conjugal, nível de escolaridade, tempo de atuação como técnico de enfermagem. Natal/RN, Brasil, 2013.

\begin{tabular}{|c|c|c|c|}
\hline \multicolumn{2}{|l|}{ Variável } & Frequência (N=21) & Percentual (\%) \\
\hline \multirow[t]{3}{*}{ Sexo } & Feminino & 21 & 100,0 \\
\hline & Masculino & 00 & 0,0 \\
\hline & Total & 21 & 100,0 \\
\hline \multicolumn{4}{|l|}{ Idade } \\
\hline & 41-45 anos & 04 & 19,1 \\
\hline & $46-50$ anos & 07 & 33,3 \\
\hline & $51-55$ anos & 07 & 33,3 \\
\hline & $56-60$ anos & 02 & 9,5 \\
\hline & Acima de 60 anos & 01 & 4,8 \\
\hline & Total & 21 & 100,0 \\
\hline \multicolumn{4}{|l|}{ Escolaridade } \\
\hline & Médio Completo & 18 & 85,7 \\
\hline & $\begin{array}{l}\text { Ensino Superior } \\
\text { Completo }\end{array}$ & 02 & 9,5 \\
\hline & $\begin{array}{l}\text { Ensino Superior } \\
\text { Incompleto }\end{array}$ & 01 & 4,8 \\
\hline & Total & 21 & 100 \\
\hline \multirow[t]{6}{*}{$\begin{array}{l}\text { Tempo de atuação } \\
\text { técnico de Enfermagem }\end{array}$} & como & & \\
\hline & 01-10 anos & 01 & 4,7 \\
\hline & 11-20 anos & 11 & 52,4 \\
\hline & $21-30$ anos & 08 & 38,1 \\
\hline & 30-40 anos & 01 & 4,8 \\
\hline & Total & 21 & 100 \\
\hline
\end{tabular}




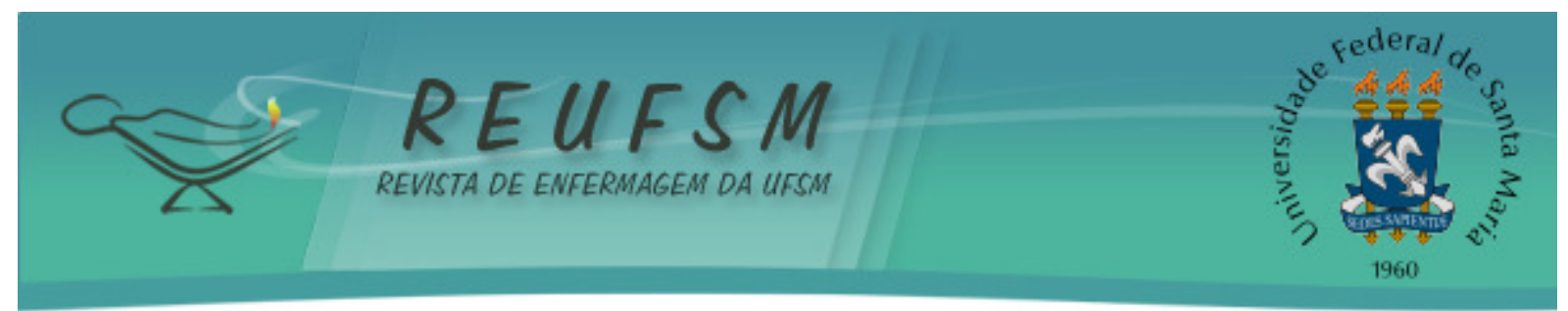

De acordo com os dados da Tabela 1, a totalidade dos participantes pertencia ao sexo feminino, fato que pode ter relação à presença expressiva de mulheres no setor saúde, principalmente em profissões nas quais o cuidado é elemento essencial, como é o caso da enfermagem. De acordo com autores, isto guarda relação com aspectos culturais que atribuem ao ser feminino características de docilidade, delicadeza e paciência, adjetivos fundamentais na oferta do cuidado. ${ }^{10-11}$

Concernente à faixa etária, observou-se que o maior número de técnicos de enfermagem possuía idade entre 46 e 55 anos. Tais achados estão em consonância com a idade produtiva para adultos no Brasil, cujo início se dá aos 15 anos e o término aos 64 anos de idade. ${ }^{12}$

Relativo ao grau de escolaridade, $18(85,7 \%)$ entrevistados possuíam ensino médio completo, exigência mínima à profissão. Ainda neste contexto, salienta-se o fato de três $(14,3 \%)$ técnicos de enfermagem terem declarado estar cursando ou já ter cursado o ensino superior.

É válido mencionar que, os técnicos de enfermagem com nível superior de escolaridade afirmaram não atuar ou não pretender atuar nas suas áreas de graduação, quais sejam as mencionadas: Saúde Pública, Enfermagem e Letras. Neste sentido, estes participantes se referiram ao ensino superior como uma forma de crescimento e qualificação pessoal e não uma possibilidade de ascensão no campo da saúde, realidade similar a identificada em outra pesquisa. ${ }^{13}$

Tratando-se do tempo de atuação como técnico de enfermagem, 11 (52,4\%) participantes exerciam esta profissão entre 11-20 anos e isto se apresenta como um aspecto positivo considerando o fato de trabalharem em um modelo assistencial o qual exige aproximação do profissional com a comunidade. Assim, entende-se que quanto maior o tempo de trabalho em um mesmo serviço, maior será a construção de laços de confiança com a população, permitindo reconhecer as reais necessidades dos indivíduos, inclusive daqueles que pouco frequentam os serviços das USF, como é o caso dos homens.

Relativo às questões específicas ao objeto de estudo, ao serem questionados quanto ao conhecimento da PNAISH, os entrevistados emitiram as respostas representadas na tabela 2.

Tabela 2 - Distribuição dos participantes da pesquisa segundo a fonte de conhecimento sobre a Política Nacional de Atenção Integral à Saúde do Homem. Natal/RN, Brasil, 2013.

\begin{tabular}{|c|c|c|}
\hline Variável & Frequência $(n=16)$ & Percentual (\%) \\
\hline $\begin{array}{c}\text { Unidade Saúde da Família } \\
\text { de saúde }\end{array}$ & $\begin{array}{l}11 \\
03\end{array}$ & $\begin{array}{l}68,8 \\
18,8\end{array}$ \\
\hline Mídia & 02 & 12,5 \\
\hline
\end{tabular}

Conforme mostra a Tabela 2, a USF foi citada por $11(68,8 \%)$ técnicos de enfermagem como a principal fonte de conhecimento sobre a PNAISH, seguida de três $(18,8 \%)$ que referiram ter participado de palestras realizadas por trabalhadores de saúde, seja no próprio ambiente de trabalho ou em eventos científicos. Estes dados apresentamse como positivos, visto salientarem os espaços das USF como apropriados para a ocorrência de discussões entre os profissionais acerca de ações e estratégias voltadas à promoção da saúde da comunidade.

Nesse sentido, entende-se ser fundamental que as USF sejam ambientes nos quais os profissionais possam discutir sobre suas ações, sobretudo quando estes são majoritariamente mulheres em busca de envolver o público masculino em medidas de 


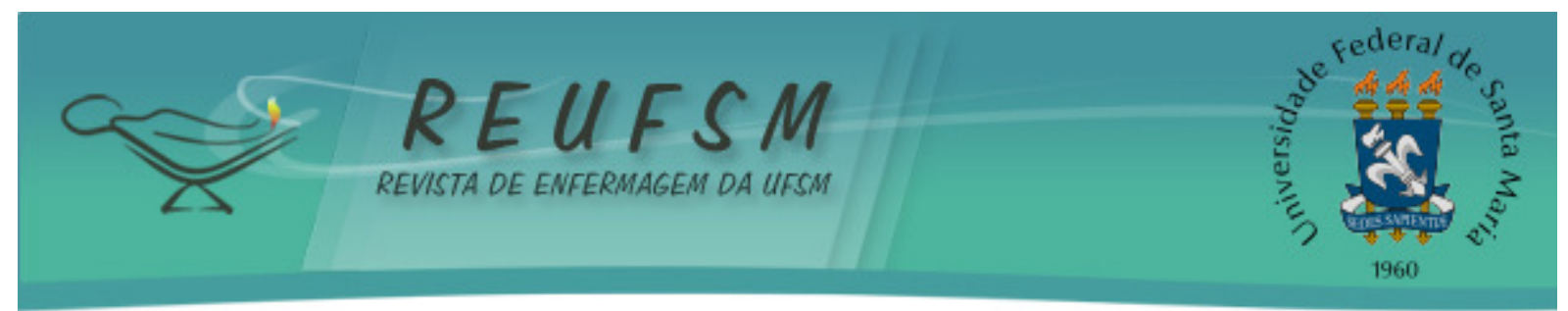

prevenção. Isto, além de impulsionar reflexões a respeito dos mecanismos de atenção ofertados à comunidade, transforma as USF em locais de aprimoramento profissional por meio da Educação Permanente em Saúde (EPS). Sobre a EPS, esta apresenta relevância no contexto da atenção primária, pois provoca transformações no processo de trabalho, qualifica os serviços de saúde e capacita os trabalhadores para a obtenção do conhecimento sobre as diferentes situações do cenário de saúde. ${ }^{13-15}$

Outra forma de aquisição do conhecimento sobre a PNAISH mencionada por dois $(12,5 \%)$ participantes foi a mídia, evidenciando o papel dos meios de comunicação na dinâmica das informações de interesse social. ${ }^{16}$ Entretanto, acredita-se que este fato tende a mostrar a ausência de discussões promovidas pelos gestores para debater o tema com os trabalhadores da saúde, levando-os a tomar conhecimento de um assunto particular de sua prática profissional por um meio comum a toda população.

Apesar de cinco entrevistados $(23,8 \%)$ terem demonstrado não possuir conhecimento sobre a PNAISH, é importante destacar que todos consideraram a política como algo benéfico à saúde do homem. Esta opinião contribui para a maior aceitação de uma nova política, sobretudo voltada a um público com o qual os profissionais não estão acostumados a lidar em suas rotinas de trabalho.

Vale destacar que os participantes também manifestaram receio em lidar com uma nova atividade, visto estarem inseridas em um sistema de saúde considerado precário, o qual, nem sempre, consegue suprir as necessidades das demandas já existentes, situação já evidenciada em outro estudo. ${ }^{17}$

Ao reconhecerem como positiva a existência da PNAISH, diversas justificativas para afirmar esta opinião foram emitidas, conforme se observa na Tabela 3.

Tabela 3 - Distribuição dos participantes da pesquisa segundo justificativas sobre a positividade da Política Nacional de Atenção Integral à Saúde do Homem. Natal/RN, Brasil, 2013.

Variável $\quad$ Frequência $(\mathrm{N}=21) \quad$ Percentual (\%)

\begin{tabular}{lll}
\hline Caráter preventivo e educativo & 10 & 47,6 \\
Estimula os cuidados masculinos com a & 04 & 19,1 \\
saúde & 03 & 14,3 \\
$\begin{array}{l}\text { Estimula a procura masculina pelos } \\
\text { serviços de saúde }\end{array}$ & & \\
$\begin{array}{l}\text { Aumenta acessibilidade masculina nos } \\
\text { serviços de saúde }\end{array}$ & 02 & 9,5 \\
$\begin{array}{l}\text { Aumenta o interesse dos profissionais } \\
\text { pela saúde do homem }\end{array}$ & 02 & 9,5 \\
\hline
\end{tabular}

A Tabela 3 mostra que a principal justificativa sobre a positividade da PNAISH emitida pela maioria dos participantes $(47,6 \%)$ esteve associada ao seu caráter preventivo e educativo. Contudo, sabendo que, medidas de promoção e prevenção à saúde ocorrem, principalmente, nos espaços internos das USF, vê-se a necessidade de novas estratégias serem elaboradas pelos profissionais, a fim de buscar ativamente a inclusão desse público em tais ações, pois se reconhece estes indivíduos como aqueles que menos frequentam instituições desse nível de complexidade.

Nessa linha de considerações, convém acrescentar que a ausência dos homens nos serviços de saúde e a necessidade de incluí-los nas ações já desenvolvidas têm sido, na concepção de estudiosos, o maior desafio para implementar a PNAISH. ${ }^{18}$ Isto porque a busca masculina por atendimento em UBS pode ser vista como uma atitude capaz de denotar fragilidade, atributo contrário aos exigidos pela sociedade machista. Por tal razão, a assistência tende a ser protelada, ocorrendo, em sua maioria, quando já há o 


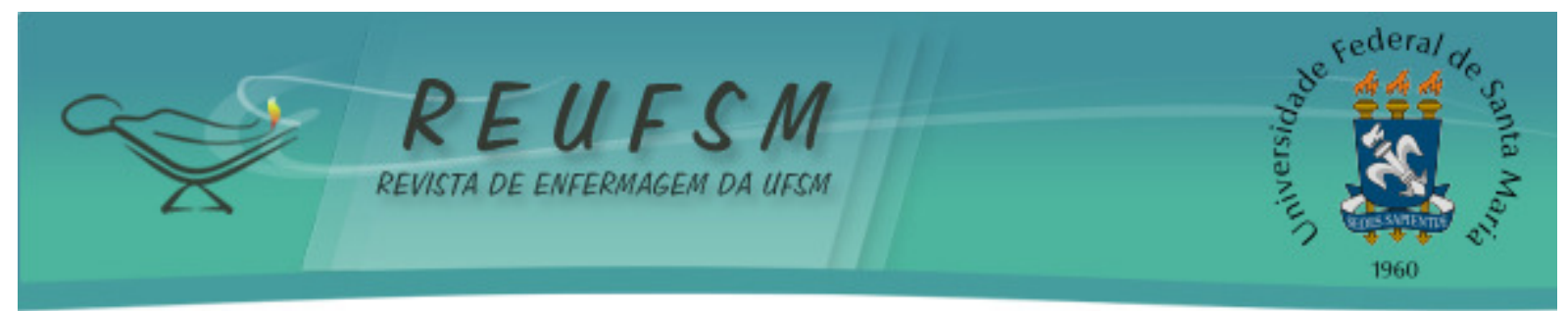

estabelecimento de doença, com sintomas que os impossibilitam de trabalharem e exercerem seus papéis de provedores. ${ }^{2,5}$

Somado as questões inerentes ao gênero, outros aspectos dificultam a inclusão masculina nos serviços de atenção primária. De acordo com o MS, há uma inadequação entre as necessidades de saúde dos homens e a estrutura de funcionamento dos serviços de atenção primária. Como exemplos desta situação podem ser citadas a compatibilidade de horários entre a jornada de trabalho e o funcionamento dos serviços de atenção primária, além das dificuldades organizacionais e de acesso, evidenciadas na demora em conseguir marcar consultas e exames. ${ }^{7}$

Essa realidade se apresenta como ponto negativo na visão deste grupo populacional, conforme verificado em outra investigação. ${ }^{2}$ Pois, considerando que o público masculino é tido, muitas vezes, como prático e objetivo, a espera em filas para conseguir atendimento pode fazê-lo desistir e adiar a busca por assistência, podendo agravar o quadro clínico ou mesmo tornar crônico o problema de saúde. ${ }^{19}$

Nesta discussão, salienta-se que as barreiras ora expostas vão de encontro ao princípio da Universalidade, o qual abrange, dentre outros aspectos, o acesso do indivíduo aos serviços de saúde, as ações de promoção à saúde, bem como a informações essenciais para manter o seu bem-estar físico e psíquico. ${ }^{20}$

Dentre os objetivos da PNAISH estão inclusos a necessidade de facilitar o acesso masculino aos servicos de saúde, como também de estimular os cuidados com a saúde e a procura destes pelos serviços de atenção primária. ${ }^{8}$ Tais objetivos, embora fossem desconhecidos pelos participantes do estudo, estiveram presentes nas respostas de quatro (20\%) e três (14\%) dos entrevistados, respectivamente.

Outra justificativa sobre os benefícios da PNAISH - emitida por dois (9,5\%) integrantes da amostra - diz respeito ao interesse dos profissionais pelas questões relacionadas à saúde do homem. Acredita-se que tais respostas estejam associadas a uma possível ampliação das ações de saúde para incluir os homens no cenário da atenção básica. Dessa forma, poderão ser vistos pelos profissionais como indivíduos também requerentes de cuidado.

Nesse sentido, reconhece-se que sensibilizar os trabalhadores da saúde para atender este segmento populacional é imperativo. Estes são personagens fundamentais para concretizar os objetivos da PNAISH, haja vista influenciarem positivamente 0 acolhimento e o acesso dos indivíduos, possibilitando a eles visualizarem os espaços das UBS como também locais de cuidados para o público masculino. ${ }^{8,17}$

Reconhecendo a importância dos profissionais de saúde na concretização da PNAISH, os participantes de pesquisa foram indagados acerca das condições que julgam serem relevantes para implementar a referida política (Tabela 4).

Tabela 4 - Distribuição dos participantes da pesquisa segundo percepção sobre as condições necessárias para implementação da Política Nacional de Atenção integral à Saúde do Homem nas Unidades Básicas de Saúde. Natal/RN, 2013.

Variável $\quad$ Frequência ( $\mathrm{N}=21) \quad$ Percentual (\%)

\begin{tabular}{lll}
\hline Capacitação da equipe de profissionais de & 07 & 33,3 \\
saúde & & 28,6 \\
Divulgação da Política & 06 & 23,8 \\
Melhoria das condições de trabalho & 05 & 14,3 \\
Maior incentivo por parte dos gestores & 03 & \\
\hline
\end{tabular}

Observa-se na Tabela 4 que, a capacitação da equipe de profissionais de saúde foi apontada como o principal aspecto a ser considerado na implementação da PNAISH pelos 


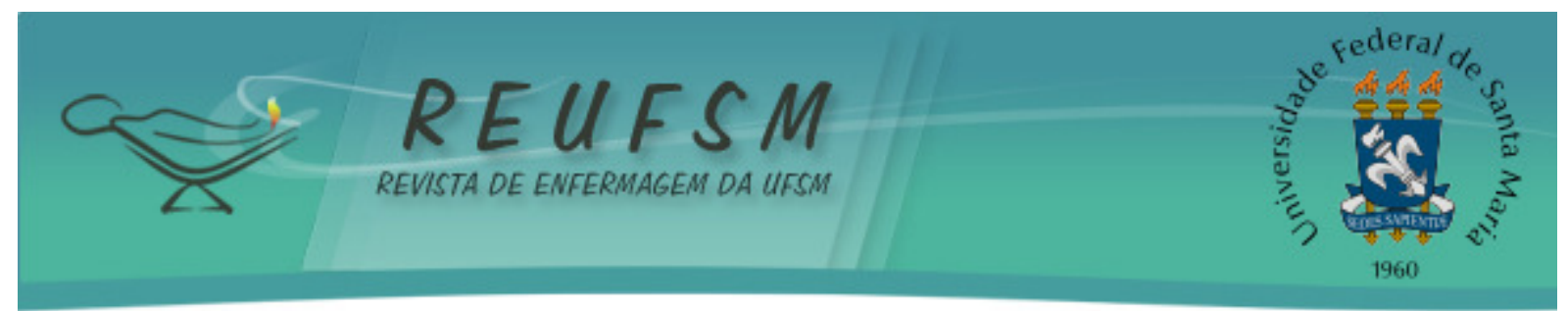

participantes. Na concepção destes, isto se deve ao déficit em suas formações profissionais que não enfocava as demandas de saúde do público masculino, situação importante para impulsionar as gestões municipais a realizarem treinamentos, cursos e ações de educação permanente envolvendo esta temática. Tal necessidade condiz com os objetivos da PNAISH que busca formar e qualificar profissionais atuantes na atenção primária com a finalidade de atender as necessidades de saúde do homem. ${ }^{8}$

Neste contexto, salienta-se o fato de os participantes da pesquisa terem informado que não foram convidados a participar de debates sobre o assunto, deixando claro, o desejo de um maior incentivo por parte dos gestores na implementação da PNAISH. Estes resultados se assemelham aos de outro estudo, no qual, a maioria dos trabalhadores de saúde entrevistados afirmou não ter recebido qualquer tipo de capacitação para assistir ao público masculino. ${ }^{1}$

Outras questões mencionadas pelos entrevistados foram: a necessidade de uma maior divulgação da política nos serviços de saúde e a melhoria das condições de trabalho com maior disponibilidade de recursos humanos, materiais, financeiros e de equipamentos. Perante estes resultados, pode-se inferir que, apesar de a PNAISH preconizar maior atenção ao público masculino nas USF, não viabiliza as condições necessárias para isto ocorrer a contento. Esta situação evidencia um distanciamento entre os objetivos da política e as ações realizadas, de fato, na atenção primária. ${ }^{1}$

Embora seja reconhecido não haver nas USF onde a pesquisa foi realizada programas nem ações específicas à população masculina, os participantes foram questionados sobre as atividades que desenvolviam para incentivar o referido público a procurarem o serviço (Tabela 5).

Tabela 5 - Distribuição dos participantes da pesquisa segundo suas ações para incentivar os homens a buscarem os serviços oferecidos nas unidades básicas de saúde. Natal/RN, 2013.

\begin{tabular}{|c|c|c|}
\hline Variável & Frequência $(\mathrm{N}=21)$ & $\begin{array}{l}\text { Percentual } \\
\text { (\%) }\end{array}$ \\
\hline $\begin{array}{l}\text { Oferece palestras junto a outros profissionais de } \\
\text { saúde }\end{array}$ & 08 & 38,1 \\
\hline Não desenvolve ações & 06 & 28,6 \\
\hline $\begin{array}{l}\text { Convite ao público masculino por ocasião das } \\
\text { reuniões de grupo e visitas domiciliares }\end{array}$ & 05 & 23,8 \\
\hline $\begin{array}{l}\text { Convite ao público masculino por ocasião de } \\
\text { procedimentos como vacinação e curativos }\end{array}$ & 02 & 9,5 \\
\hline
\end{tabular}

Diante dos dados expostos na Tabela 5, o maior número de participantes admitiu que suas ações para incentivar o grupo masculino a ir à USF estiveram voltadas a palestras junto com outros profissionais de saúde. Esta realidade é propícia, visto tais trabalhadores estarem exercendo seus papéis de educadores em saúde em suas práticas.

Entretanto, a oferta de palestras não é um hábito rotineiro, são eventos pontuais, tendo em vista acontecerem em datas específicas, como o dia dos pais ou em decorrência de campanhas de saúde. Ademais, considerando que os homens adultos jovens pouco frequentam os serviços de saúde ${ }^{2,6}$, entende-se ser a palestra uma estratégia limitada a homens idosos ou com alguma doença crônica instalada, os quais já buscam as USF para receber medicamentos e participar de grupos de idosos.

Esse mesmo impasse é vivenciado por aqueles que referiram convidar os homens a buscar assistência por ocasião das visitas domiciliares. Pois, considerando o fato de o horário das referidas visitas ocorrer no mesmo período em que este público encontra-se desenvolvendo suas atividades laborais, a maior parcela de indivíduos a ser abrangida por 


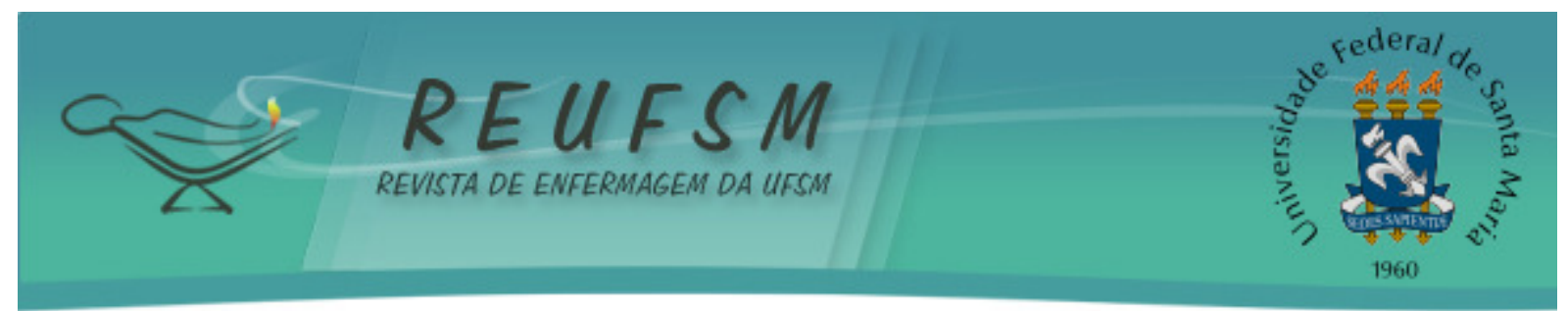

esta ação permanece sendo os idosos, haja vista os homens em idade produtiva geralmente não se encontram em seus domicílios.

Tratando-se da ação citada por dois $(9,5 \%)$ participantes referente à realização do convite ao homem quando este busca à UBS para realizar algum procedimento como curativos e vacinação, esta se apresenta como proveitosa para divulgar as ações ofertadas pelo serviço a estes indivíduos. Além disso, possibilita informá-los sobre prevenção e cuidados com a saúde, inclusive acerca de situações que desencadearam a busca por assistência.

Diante disso, percebe-se que as ações desenvolvidas pelos técnicos de enfermagem estão pautadas em convites realizados nos espaços das USF e domiciliares. Entretanto, pelo fato de os homens não serem encontrados em tais locais, reduz-se as possibilidades de êxito deste tipo de intervenção. ${ }^{2}$

Esta realidade poderia ser minimizada com buscas ativas por esses indivíduos em espaços nos quais eles poderão ser facilmente encontrados, como, por exemplo, nas empresas onde trabalham. Deste modo, vê-se a importância de pactuar as diferentes esferas sociais, no intuito de ampliar e favorecer a saúde masculina, fato exposto na própria PNAISH. ${ }^{8}$

É importante ressaltar o fato de seis $(28,6 \%)$ dos técnicos de enfermagem terem declarado não realizar ações voltadas para a população masculina, sendo alegada a falta de incentivo por parte da equipe de saúde e carência de conhecimento sobre o assunto. Mediante a esta realidade, entende-se ser imprescindível ampliar as discussões no ambiente da UBS, visando envolver todos os profissionais de saúde na efetiva implementação da PNAISH, de modo a garantir uma assistência integral e pautada nas reais necessidades dos homens.

\section{CONCLUSÃO}

Os resultados obtidos com a realização deste estudo responderam ao questionamento de pesquisa. Sendo assim, a maioria dos participantes revelou ter conhecimento da existência da PNAISH e ter adquirido informações a este respeito em seu local de trabalho. Embora tenha existido uma parcela de entrevistados que demonstrou não conhecer a política, a totalidade da amostra emitiu uma opinião positiva quanto à sua existência. Ao emitirem opiniões favoráveis neste âmbito, foram citadas inúmeras justificativas entre as quais se salienta o fato de a PNAISH possuir caráter preventivo e educativo.

Destaca-se, ainda, a opinião emitida pelos participantes quanto às condições necessárias para a implementação da política, sendo a capacitação dos trabalhadores a mais citada. Esta realidade evidencia a importância de preparação das equipes de assistência para o trabalho com novas políticas de saúde, principalmente quando relacionadas à saúde do homem, haja vista este ser um tema novo e pouco discutido nos ambientes de saúde.

Diante disto, reconhece-se a necessidade de a PNAISH ser melhor propagada entre os profissionais de saúde, no intuito de viabilizar mecanismos capazes de facilitar a sua efetiva implementação na prática das USF. Considerando que os técnicos de enfermagem possuem em suas atribuições nas equipes da ESF a assistência direta a toda comunidade, reconhece-os como elementos chave fundamentais para contribuir consubstancialmente na ampliação do acesso do público masculino aos serviços de atenção primária.

\section{REFERÊNCIAS}

1. Aguiar ZN. SUS: Sistema Único de Saúde: antecedentes, percurso, perspectivas e desafios. São Paulo: Martinari; 2011. 


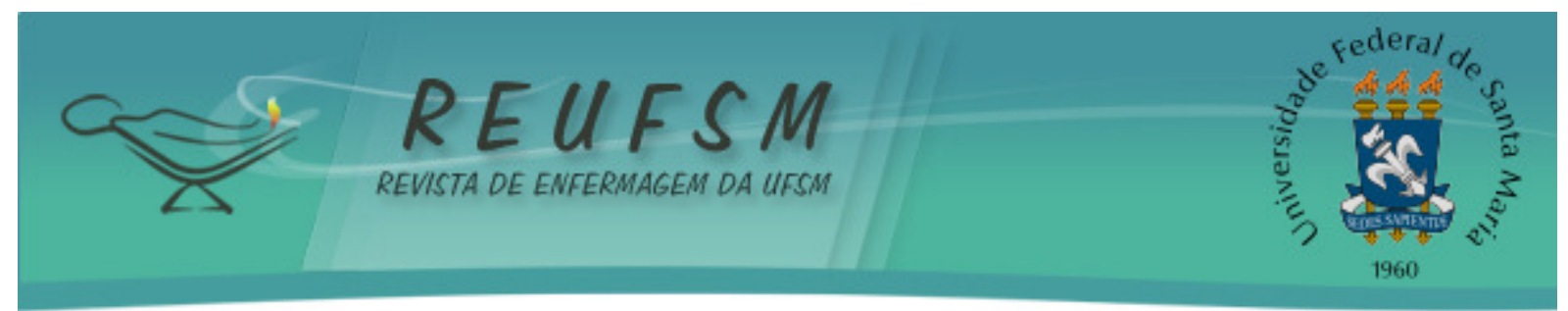

2. Brito RS, Santos DLA, Maciel PSO. Olhar masculino acerca do atendimento na Estratégia Saúde da Família. Rev RENE [Internet]. 2010 [acesso em 2013 ago 26];11(4):135-42. Disponível http://www.revistarene.ufc.br/revista/index.php/revista/article/view/437.

em:

3. Costa GD, Cotta RMM, Ferreira MLSM, Reis JR, Franceschini SCC. Saúde da família: desafios no processo de reorientação do modelo assistencial. Rev Bras Enferm. 2009;62(1):113-8.

4. Loch-Neckel G, Seemann G, Eidt HB, Rabuske MM, Crepaldi MA. Desafios para a ação interdisciplinar na atenção básica: implicações relativas à composição das equipes de saúde da família. Ciênc Saúde Coletiva. 2009;14 Supl 1:1463-72.

5. Figueiredo WS, Schraiber LB. Concepções de gênero de homens usuários e profissionais de saúde de serviços de atenção primária e os possíveis impactos na saúde da população masculina. Ciênc Saúde Coletiva. 2011;16 Supl 1:935-44.

6. Gomes R, Moreira MCN, Nascimento EF, Rebello LEFS, Couto MT, Schraiber LB. Os homens não vêm! Ausência e/ou invisibilidade masculina na atenção primária. Ciênc Saúde Coletiva. 2011;16 Supl 1:983-92.

7. Gomes R. Sexualidade masculina, gênero e saúde. Rio de Janeiro: Fiocruz; 2008.

8. Brasil. Ministério da Saúde. Secretaria de Atenção à Saúde. Departamento de Ações Programáticas e Estratégicas. Política Nacional de Atenção integral à Saúde do Homem princípios e diretrizes. Brasília (DF): Ministério da Saúde; 2009. (Série B. Textos Básicos de Saúde).

9. Brasil. Ministério da Saúde. Conselho Nacional de Saúde. Resolução CNS n 196, de 10 de outubro de 1996. Aprova diretrizes e normas regulamentadoras de pesquisa envolvendo seres humanos. Brasília (DF); 1996.

10. Barbosa RHS, Menezes CAF, David HMSL, Bornstein VJ. Gênero e trabalho em saúde: um olhar crítico sobre o trabalho de agentes comunitárias/os de saúde. Interface Comunic Saúde Edu. 2012;16(42):751-65.

11. Machado MH, Vieira ALS, Oliveira E. Construindo o perfil da enfermagem. Enferm Foco [Internet]. 2012 [acesso em 2013 ago 26];3(3):119-22. Disponível em: http://revista.portalcofen.gov.br/index.php/enfermagem/article/view/294.

12. Instituto Brasileiro de Geografia e Estatística (IBGE). Indicadores Sociais Mínimos. Conceitos [Internet]. Rio de Janeiro; 2014 [acesso em 2014 set 2]. Disponível em: http:// http://www.ibge.gov.br/home/estatistica/populacao/condicaodevida/indicadoresminimos /conceitos.shtm.

13. Ximenes Neto FRG, Costa MCF, Rocha J, Cunha ICKO. Auxiliares e técnicos de enfermagem na saúde da família: perfil sociodemográfico e necessidades de qualificação. Trab Educ Saúde [Internet]. 2008 [acesso em 2013 ago 26];6(1):51-64. Disponível em: http://www.revista.epsjv.fiocruz.br/upload/revistas/r197.pdf.

14. Julião GG, Weigell LD. Atenção à saúde do homem em unidades de Estratégia Saúde da Família. Rev Enferm UFSM [Internet]. 2011 [acesso em 2013 ago 26];1(2):144-52. Disponível em: http://cascavel.ufsm.br/revistas/ojs-2.2.2/index.php/reufsm/article/view/2400.

15. Sarreta FO. Educação permanente em saúde para os trabalhadores do SUS [Internet]. São Paulo: Editora UNESP; 2009 [acesso em 2014 set 2]. Disponível em: http://books.scielo.org/id/29k48. 


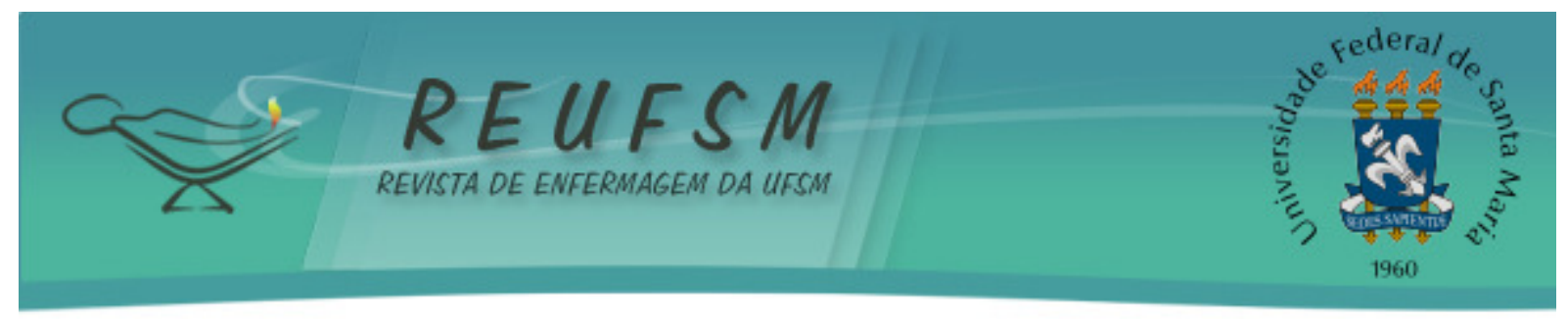

16. Paiva R. O retorno da comunidade: os novos caminhos do social. Rio de Janeiro: Mauad $\mathrm{X} ; 2007$.

17. Leal AF, Figueiredo WS, Nogueira-da-Silva GS. O percurso da Política Nacional de Atenção Integral à Saúde do Homem (PNAISH), desde a sua formulação até sua implementação nos serviços públicos locais de atenção à saúde. Ciênc Saúde Coletiva. 2012;17(10):2607-16.

18. Knauth DR, Couto MT, Figueiredo WS. A visão dos profissionais sobre a presença e as demandas dos homens nos serviços de saúde: perspectivas para a análise da implantação da Política Nacional de Atenção Integral à Saúde do Homem. Ciênc Saúde Coletiva. 2012;17(10):2617-26.

19. Gomes R, Nascimento EF, Araújo FC. Por que os homens buscam menos os serviços de saúde do que as mulheres? As explicações de homens com baixa escolaridade e homens com ensino superior. Cad Saúde Pública. 2007;23(3):565-74.

20. Pontes APM, Cesso RGD, Oliveira DC, Gomes AMT. O princípio de universalidade do acesso aos serviços de saúde: o que pensam os usuários? Esc Anna Nery Rev Enferm [Internet]. 2009 [acesso em 2013 set 1];13(3):500-7. Disponível em: http://www.scielo.br/pdf/ean/v13n3/v13n3a07.

Data de recebimento: 22/09/2013

Data de aceite: 17/10/2014

Contato com autor responsável: Danyelle Leonette Araújo dos Santos

Endereço postal: Campus Universitário, Departamento de Enfermagem, Br. 101. Lagoa

Nova. CEP: 59.072-970. Natal/RN.

E-mail: danyleonette@gmail.com 